\title{
Analysis of Aircraft's Static Pressure Installation Residual Error Requirements
}

\author{
Yang Hui ${ }^{1,}$ a , Yang Shipu, ${ }^{1, b}$ \\ ${ }^{1}$ Shanghai Aircraft Design and Research Institute, Shanghai, China \\ aya_ben_cool@126.com, byangshipu@comac.cc
}

Keywords: aircraft, static pressure, airworthiness

Abstract. Some specific airworthiness regulations about the precision of the velocity, pressure and height measurement have listed and formulated here. Computation are done to get the exactly value of the requirements about static pressure residual installation error at a range of height and velocity.

\section{Introduction}

Modern air data instruments and modules provide primary or backup capability to measure a number of critical parameters for aircraft flight and navigation. These include altitude, airspeed, Mach number, rate of vertical change and so on. The two fundamental pressure measurements required to provide these parameters are static (barometric) air pressure, and the total pressure. These measurements are coupled with temperature readings and correction factors in air data computers, which use algorithms of varying complexity and look-up tables to compute the parameters of interest ${ }^{[1]}$.

The local pressure can be measured with a pitot-static tube or a flush-mounted port on the fuselage. Figure 1 shows a typical pitot-static tube. Certain calibrations need to be made to get the true static pressure ${ }^{[2]}$. Even with the correction, some pressure errors will remain. These errors are called residual installation error, installation error, for short. To guarantee the aircraft's safety, the pressure installation error should be satisfied the specific airworthiness regulations.

In this chapter, these specific regulations about the velocity, pressure and height measurement have listed and formulated. Computation have been done to get the exactly value of the requirements about static pressure residual installation error at a range of height and velocity.

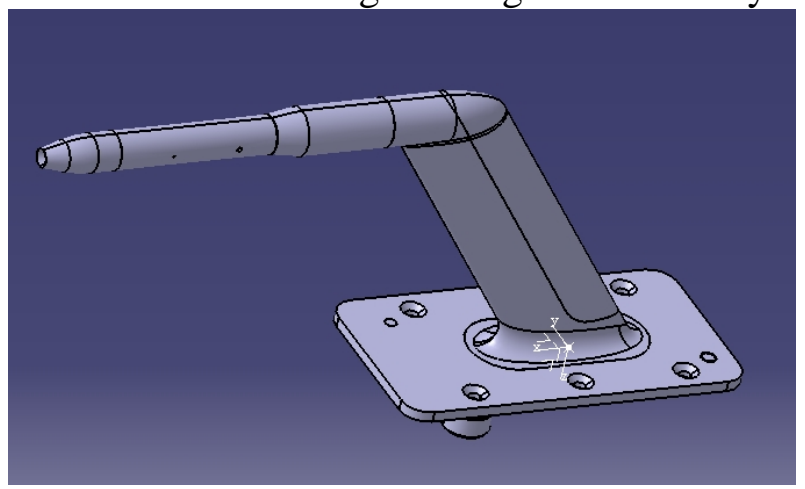

Fig.1 Diagram of typical pitot-static tube

\section{Airworthiness Regulations}

The airworthiness regulations related to pressure installation residual error are ${ }^{[3][4]}$ :

- CCAR 25.1323 "Airspeed indicating system"; and

- CCAR 25.1325 "Static Pressure system"; and

- Appendix D to CCAR 91 "Operations in Reduced Vertical Separation Minimum (RVSM) Airspace".

CCAR 25.1323(c). The airspeed error of the installation, excluding the airspeed indicator instrument calibration error, may not exceed three percent or five knots, whichever is greater, throughout the speed range, from- 
- $\mathrm{V}_{\mathrm{MO}}$ to $1.23 \mathrm{~V}_{\mathrm{SR} 1}$ with flaps retracted; and

- $1.23 \mathrm{~V}_{\mathrm{SR} 0}$ to $\mathrm{V}_{\mathrm{FE}}$ with flaps in the landing position.

Fig. 2 is the diagram of the requirement of airspeed installation error.

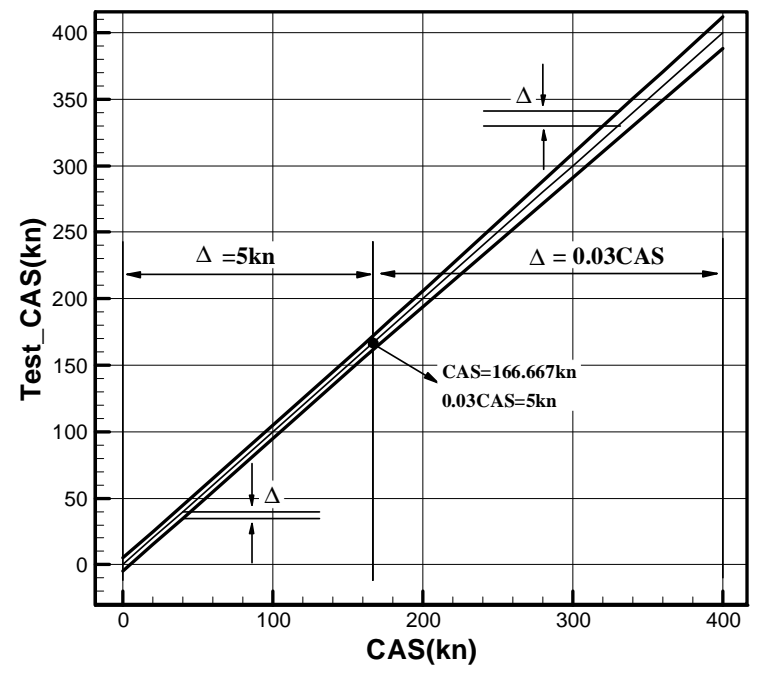

Fig.2 Requirement of airspeed installation error:

CCAR 25.1325(e). Each system must be designed and installed so that the error in indicated pressure altitude, at sea level, with a standard atmosphere ${ }^{[5]}$, excluding instrument calibration error, does not result in an error of more than \pm 30 feet per 100 knots speed for the appropriate configuration in the speed range between $1.23 \mathrm{~V}_{\mathrm{SR} 0}$ with flaps extended and $1.7 \mathrm{~V}_{\mathrm{SR} 1}$, with flaps retracted. However, the error need not be less than \pm 30 feet.

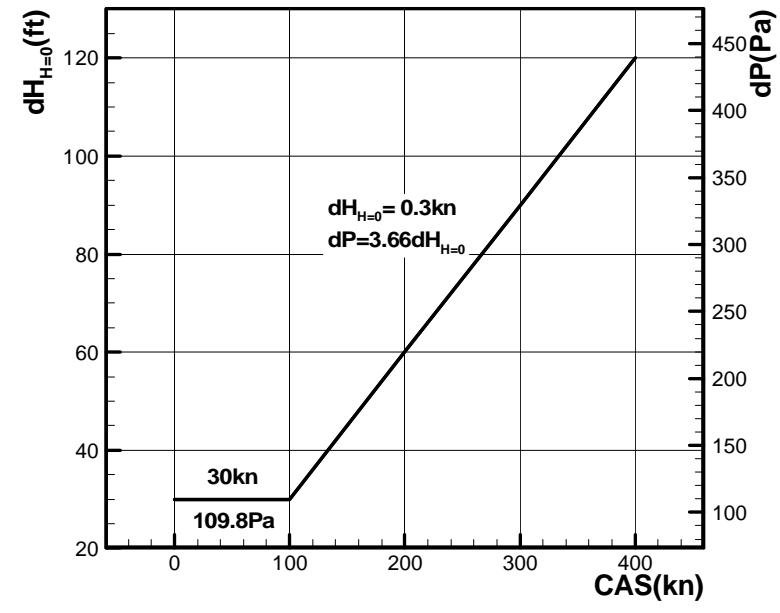

Fig.3 Requirement of indicated pressure altitude installation error

Appendix D to CCAR 91. For each condition in the basic RVSM flight envelope, the largest combined absolute value for residual static source error plus the avionics error may not exceed 160 feet.

\section{Theory and Formula}

Standard Atmosphere. There are several atmosphere standards which have been established. In this chapter, the standard model is in international standard atmosphere (ISA). The properties of ISA is:

- At sea level, $\mathrm{T}_{0}=15 \square=288.15 \mathrm{~K}, \mathrm{P}_{0}=101325 \mathrm{~Pa}=760 \mathrm{mmHg}, \rho_{0}=1.225 \mathrm{~kg} / \mathrm{m} 3$;

- Barometic height formula (Pressure variation with height):

a) $0 \leq H \leq 11000 \mathrm{~m}$, 


$$
P_{S}=P_{0}\left(1-\frac{0.0065 H}{T_{0}}\right)^{\frac{g}{0.0065 R}}
$$

Where

$P_{0}--$ pressure at sea level, $\mathrm{Pa}$;

$T_{0}--$ temperature at sea level, $\mathrm{K}$;

$\mathrm{g}=9.80665 \mathrm{~m} / \mathrm{s}^{2}$

$\mathrm{R}=287.053 \mathrm{~J} / \mathrm{Kg} \cdot \mathrm{K}$.

b) $11000 \leq H \leq 20000 \mathrm{~m}$,

$$
P_{S}=P_{11} e^{-\frac{g}{R T_{11}}(H-11000)}
$$

Where

$P_{11}$ - pressure at $\mathrm{H}=11000 \mathrm{~m}, P_{11}=22631.8 \mathrm{~Pa}$;

$T_{11}-$ temperature at $\mathrm{H}=11000 \mathrm{~m}, T_{11}=216.65 \mathrm{~K}$.

Calibrated Airspeed(CAS). Calibrated airspeed can be written as a function of total pressure and static pressure, as

$$
P_{T}-P_{S}=P_{0}\left(\left(1+0.2\left(\frac{C A S}{a_{0}}\right)^{2}\right)^{3.5}-1\right)
$$

Where

$P_{T}-$ total pressure measured by total sensor, correction with instrument error and location error;

$P_{S}-$ static pressure measured by static sensor, correction with instrument error and location error;

$P_{0}-$ pressure at sea level with the standard atmosphere;

$a_{0}-$ sonic speed at sea level with the standard atmosphere.

\section{Formula.}

The relationship between the pressure measurement error and airspeed installation error. For differential equation (3), the relationship between the pressure measurement error and airspeed installation error is derived, as

$$
\begin{aligned}
& d\left(P_{T}-P_{S}\right) \\
& =P_{0} * 3.5\left(1+0.2\left(\frac{C A S}{a_{0}}\right)^{2}\right)^{2.5} * 0.2 * 2 C A S / a_{0}^{2} d C A S=1.4 P_{0}\left(1+0.2\left(\frac{C A S}{a_{0}}\right)^{2}\right)^{2.5} * C A S / a_{0}^{2} d C A S \\
& =1.225\left(1+1.7271 * 10^{-6} C A S^{2}\right)^{2.5} C A S d C A S
\end{aligned}
$$

Where, the unit of CAS is $\mathrm{m} / \mathrm{s}$, the unit of $\mathrm{P}_{\mathrm{T}}$ and $\mathrm{P}_{\mathrm{S}}$ is $\mathrm{Pa}$.

The relationship between the pressure measurement error and pressure altitude error. For differential equation (1) and (2), the relationship between the pressure measurement error and pressure altitude error is derived, as

a) $0 \leq H \leq 11000 \mathrm{~m}$,

$$
d P_{S}=P_{0} * \frac{g}{0.0065 R}\left(1-\frac{0.0065 H}{T_{0}}\right)^{\frac{g}{0.0065 R}}-1 *\left(-\frac{0.0065}{T_{0}}\right) d H=-12.01\left(1-2.256^{*} 10^{-5} H\right)^{4.259} d H
$$

b) $11000 \leq H \leq 20000 \mathrm{~m}$, 


$$
d P_{S}=-\frac{g}{R T_{11}} P_{S} d H=-1.5777 * 10^{-4} P_{S} d H
$$

Where, the unit of $\mathrm{H}$ is $\mathrm{m}$, the unit of $\mathrm{P}_{\mathrm{S}}$ is $\mathrm{Pa}$.

\section{Results}

For some aircraft, the velocity scope of the airworthiness regulations requirement is as Fig.4, Fig.5 and Fig.6. The avionics error is as shown in Fig.7. From the regulation about appendix D to CCAR 91, the combined absolute value for residual static source error plus the avionics error may not exceed 160 feet, so we can get the requirement of residual static source error by minus, as Fig.8.

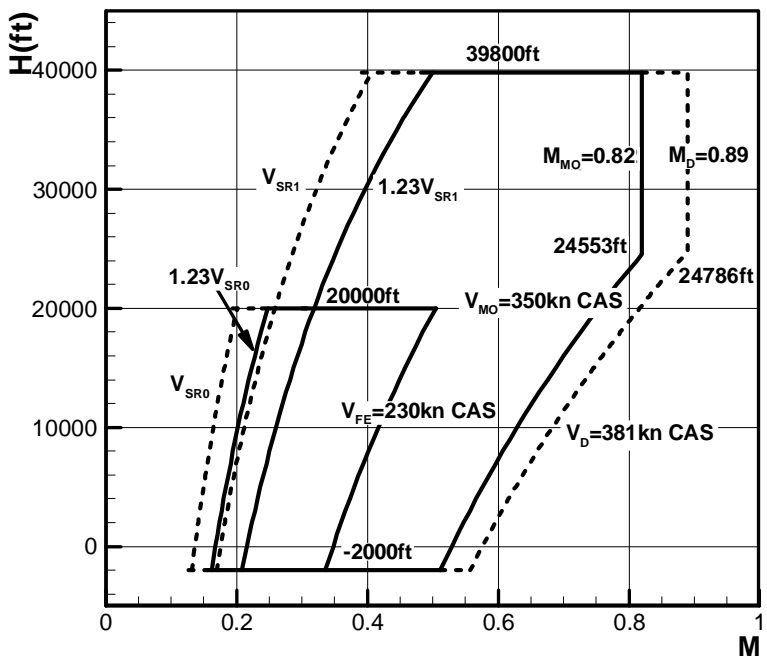

Fig.4 Velocity-height envelope of airspeed installation error requirement

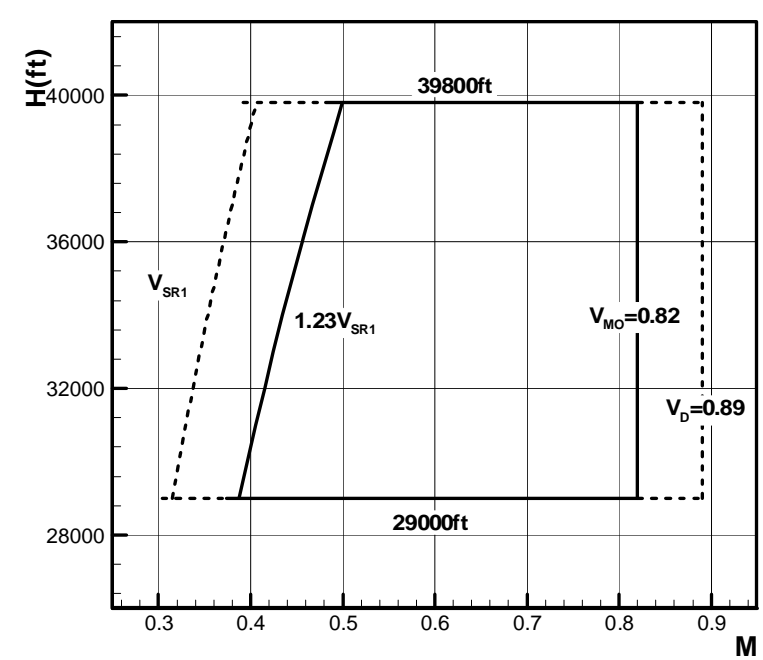

Fig.6 RVSM flight envelope

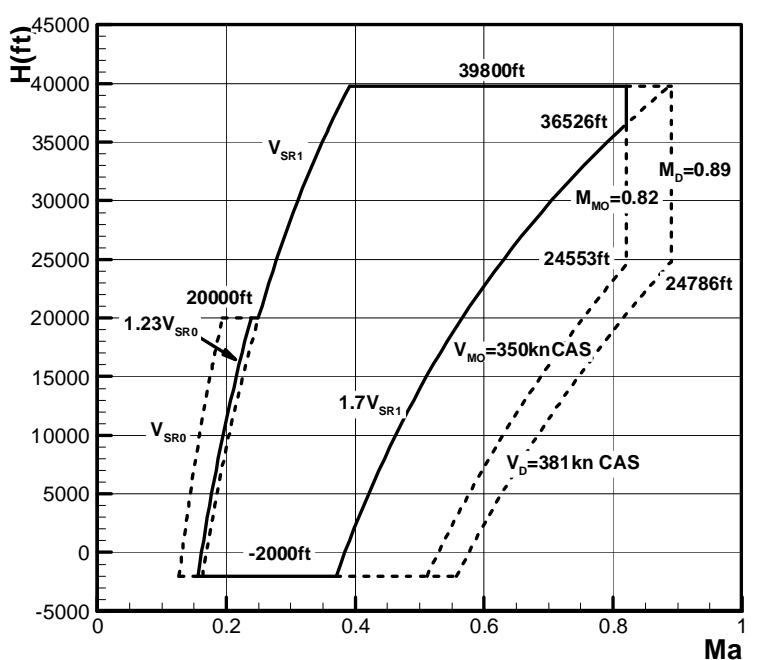

Fig.5 Velocity-height envelope of pressure altitude error requirement

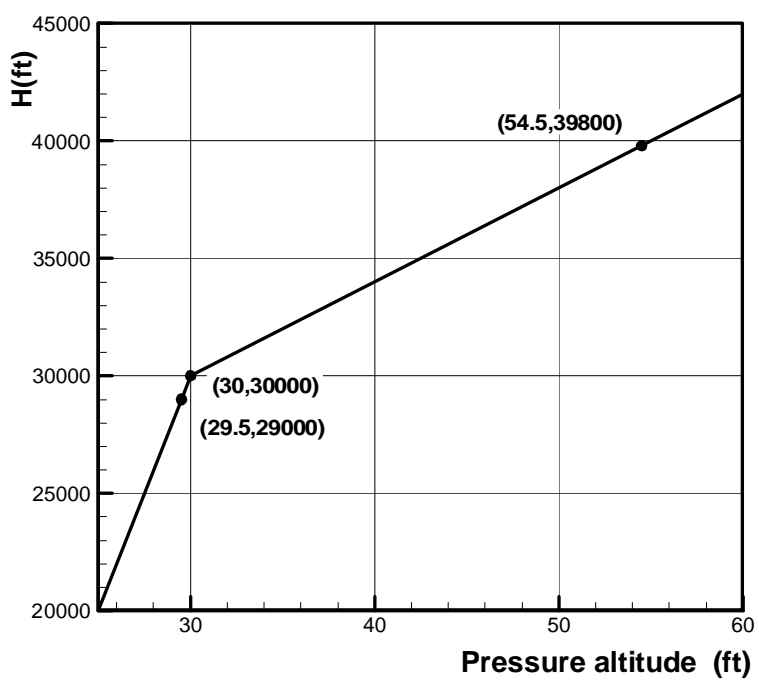

Fig.7 Avionics error 


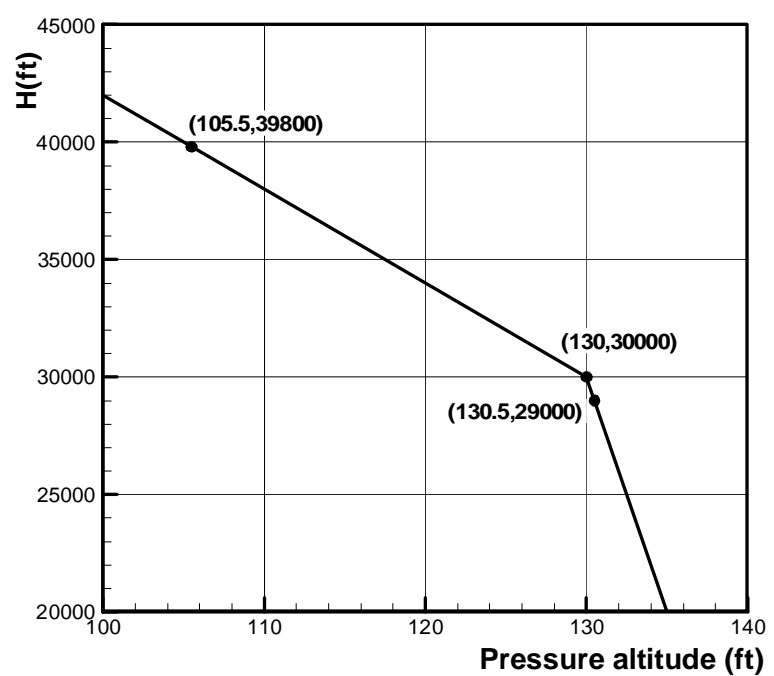

Fig.8 Residual static source error requirement at RVSM flight envelope

The mathematical expression of CCAR-25.1325(e) is

$$
\left|(d H)_{H=0}\right|_{\max }= \begin{cases}30 f t & V<100 k n \\ 0.3 V f t & V \geq 100 k n\end{cases}
$$

Combining with equation (5), where $\mathrm{H}=0 \mathrm{~m}$ is used, yields the value for static pressure installation error requirement at a range height within the specified velocity, see Fig.9a). By dividing the free filed static pressure, yields the relative value of static pressure installation error requirement, see Fig.9b).

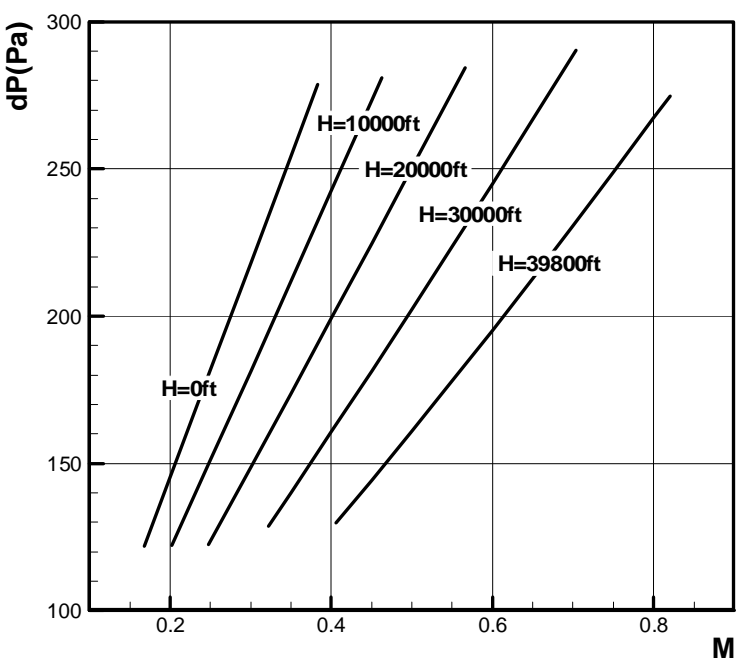

a) Absolute value

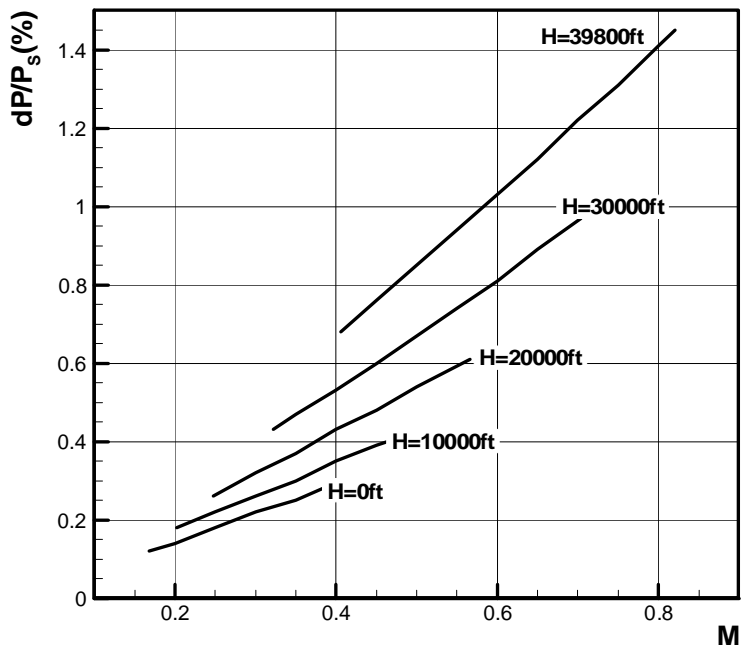

b) Relative value

Fig.9 Static pressure installation error requirement (CCAR-15.1325)

From the regulation about appendix D to CCAR 91, we can get the requirement of pressure altitude error. Combing the equation (5) and (6), yields the value for static pressure installation error requirement at a range height, see Fig.10. Compare the value for the CCAR-91 requirement and CCAR-25 requirement, the requirement of CCAR-91 is more stringent for the aircraft's static pressure measurement at airline operation, see Fig.11. 


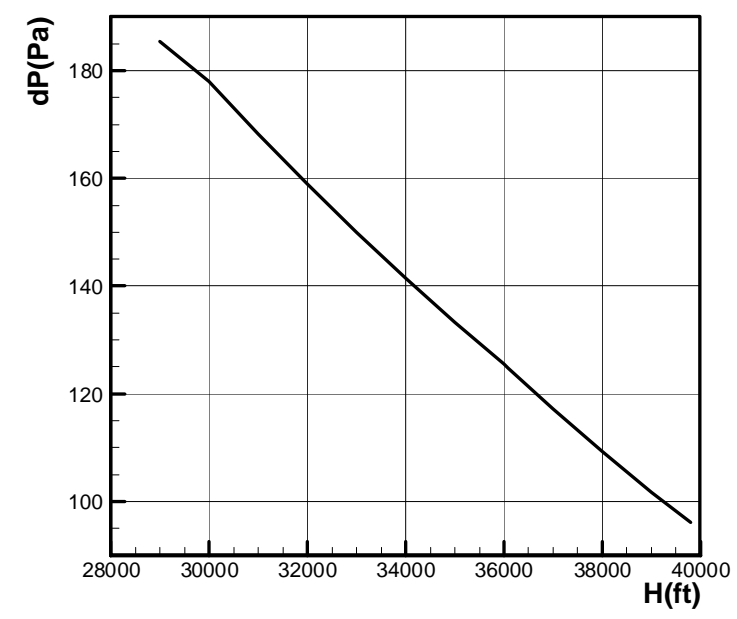

a) Absolute value

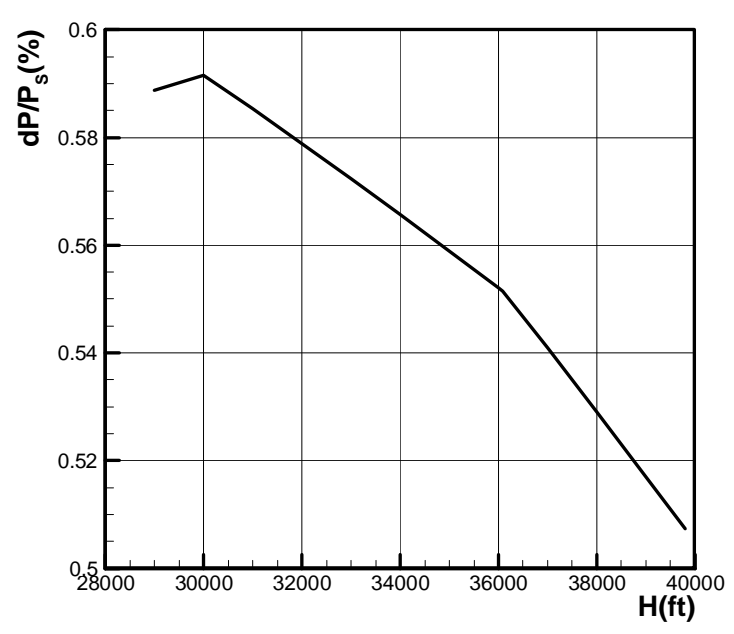

b) Relative value

Fig.10 Static pressure installation error requirement (CCAR-91)

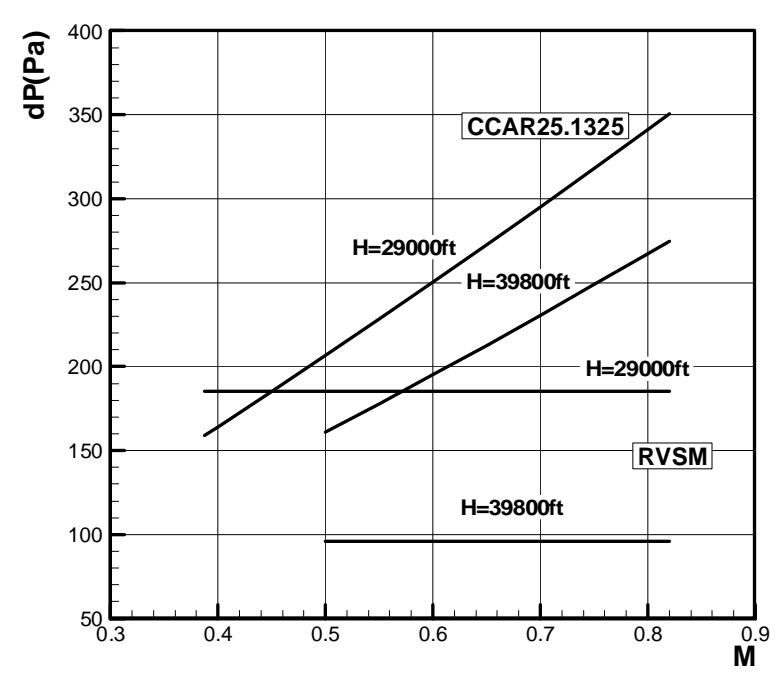

a) Absolute value

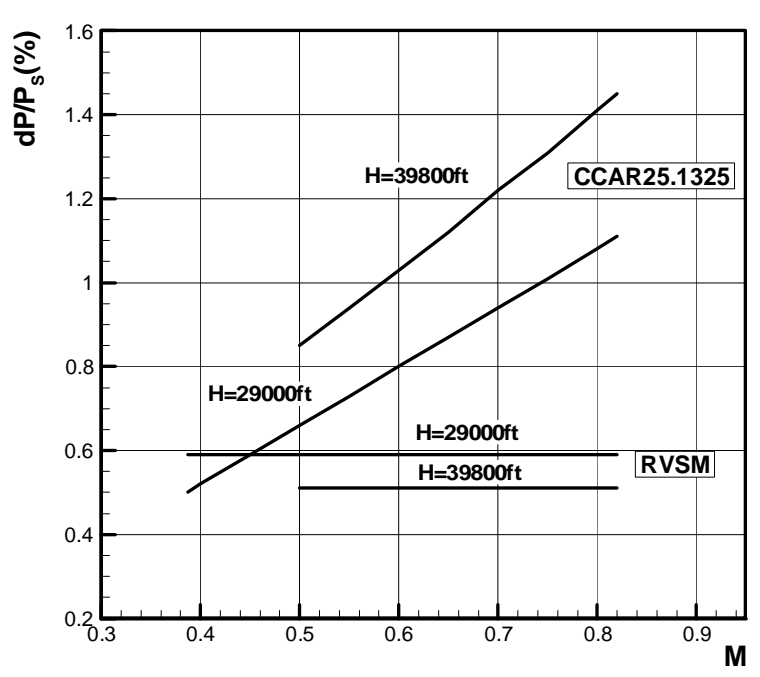

b) Relative value

Fig.11 Static pressure installation error requirement (comparison between CCAR-91and CCAR-25.1325)

From the regulation about CCAR-25. 1323 “Airspeed indicating system”, yields

$$
|d C A S| \leq \max \{5 k n, 0.03 C A S\}
$$

Where, the unit of CAS is knot. Substituting into equation (4), and assuming that the total pressure measurement error is zero, yields the value about static pressure installation error requirement. The total pressure measurement error is very small, so the assumption is appropriate. 


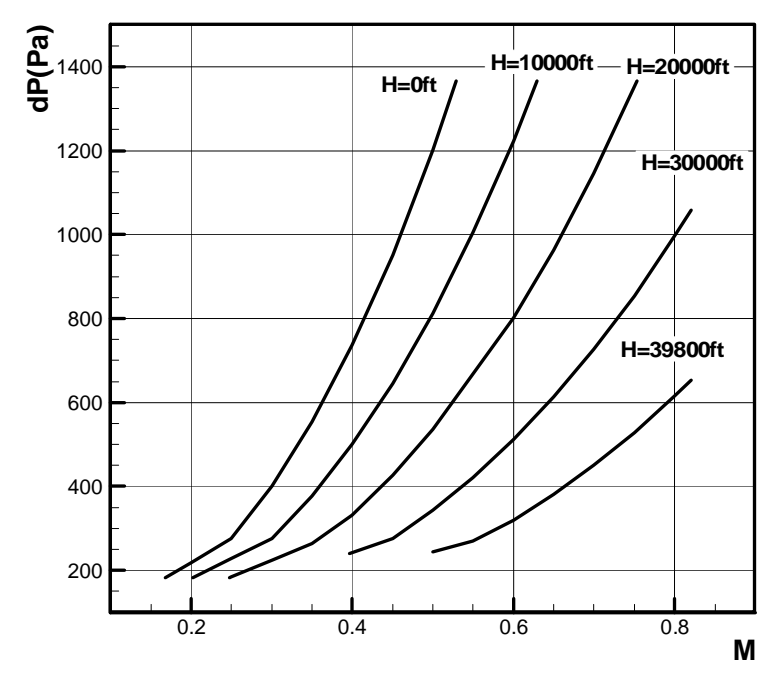

a) Absolute value

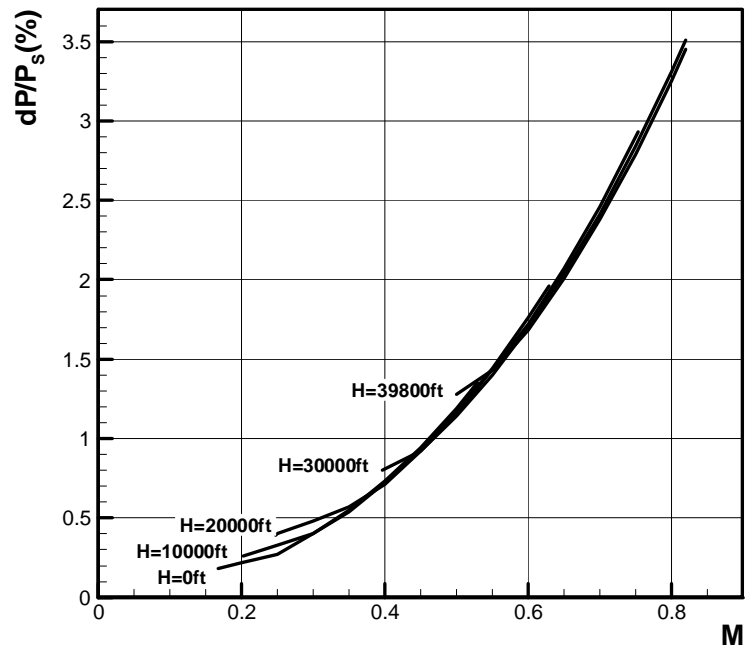

b) Relative value

Fig.12 Static pressure installation error requirement (CCAR-25.1323)

\section{References}

[1] Kim Wiolland. Air data Computers[N]. Avionices News, January 2005: 46-49.

[2] Qian Guoning. Static Source Error Correction and Application in Air Data Computer[J]. Acta Aeronautica Et Astronautica Sinica, Vol.10, No.4, Apr. 1989.

[3] CCAR-25-R4 Civil Aviation Regulation of China,"Airworthiness standards: Transport Category Airplanes"[S].China, Civil Aviation Administration, 2011.

[4] CCAR-91 General Operating And Flight Rule[S]. China, Civil Aviation Administration,2007.

[5] Pitot-Statics and the Standard Atmosphere[R] USAF Test Pilot School, Edwards Afb, CA,1996. 